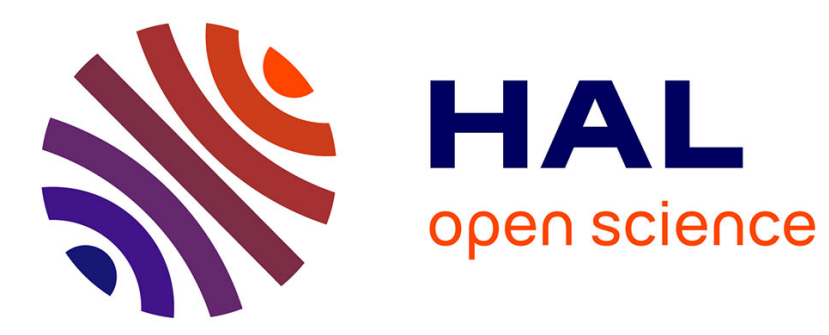

\title{
Channel Choice Complications
}

Christian Østergaard Madsen, Sara Hofmann, Willem Pieterson

\section{To cite this version:}

Christian Østergaard Madsen, Sara Hofmann, Willem Pieterson. Channel Choice Complications. 18th International Conference on Electronic Government (EGOV), Sep 2019, San Benedetto del Tronto, Italy. pp.139-151, 10.1007/978-3-030-27325-5_11. hal-02445798

\section{HAL Id: hal-02445798 \\ https://hal.inria.fr/hal-02445798}

Submitted on 20 Jan 2020

HAL is a multi-disciplinary open access archive for the deposit and dissemination of scientific research documents, whether they are published or not. The documents may come from teaching and research institutions in France or abroad, or from public or private research centers.
L'archive ouverte pluridisciplinaire HAL, est destinée au dépôt et à la diffusion de documents scientifiques de niveau recherche, publiés ou non, émanant des établissements d'enseignement et de recherche français ou étrangers, des laboratoires publics ou privés. 


\title{
Channel Choice Complications Exploring the multiplex nature of citizens' channel choices.
}

\author{
Christian Østergaard Madsen ${ }^{1}(\nabla)$, Sara Hofmann ${ }^{2}$ and Willem Pieterson ${ }^{3}$ \\ ${ }^{1}$ IT University of Copenhagen, Denmark \\ chrmeitu.dk \\ ${ }^{2}$ University of Agder, Norway \\ sara.hofmann@uia.no \\ ${ }^{3}$ Center for eGovernment Studies, the Netherlands \\ willemepieterson.com
}

\begin{abstract}
In spite of massive investment and increased adoption of digital services, citizens continue to use traditional channels to interact with public organizations. The channel choice (CC) field of research tries to understand citizens' interactions with public authorities to make the interaction more efficient and increase citizen satisfaction. However, most studies have been conducted either as surveys of hypothetical services or in experimental settings, leading to a lack of empirical data from actual use contexts. Therefore, we present the results of a sequential mixed methods study which combines observations of citizen-caseworker interaction in a call center, contextual interviews with callers, and a survey classifying topics from 10,000 telephone calls. We contribute to the CC field and practice with rich empirical data from studies of actual channel choices. Specifically, the study explores the multiplex nature of real-life CC and demonstrate how telephone calls can be part of a process, which occurs across both traditional and digital channels. Moreover, we identify problems, which cause telephone calls related to digital services, and classify these in two groups: information related problems and action related problems.
\end{abstract}

Keywords: Channel Choice, Mixed Methods, Public Services, e-Government, Multi-Channel Management, Channel Behavior, Udbetaling Danmark.

\section{Introduction}

To reduce costs, governments seek to migrate interaction with citizens from traditional channels to digital self-service channels. Early e-government studies assumed this process would happen automatically with the adoption of digital channels [1]. Recent studies, however, demonstrate that this is not always the case [2]. In Canada, the use of websites declined between 2008 and 2012 [3]. The continued use of traditional channels also occurs in settings where digital self-service channels are widely adopted, for example in Denmark [4], a leader in e-government [5]. The question is why this happens. While many multi-channel management scholars $[6,7]$ have argued that electronic channels will not replace traditional ones [8], they do not explain why use of traditional channels remains so important. One possible explanation lies in the nature of existing research and theory on citizens' channel behaviors [9] and how these channel behaviors 
are incorporated in models of multi-channel service delivery [7]. First of all, most studies have focused on citizens' initial and singular choice of a single channel. Next, most studies have focused on discrete channel choices in clearly described situations. Lastly, most research is quantitative and revolves around building and testing hypothetical variance models based on surveys. This leads to two shortcomings of existing $\mathrm{CC}$ research:

1. By studying channel choices in isolation, studies ignore the possibility that channel choices can have a sequential or multiplex (see below) nature. For example, calling an organization after failing to find information online.

2. By asking to choose a single channel in hypothetical situations, studies ignore that channel choices and uses could happen in parallel. For example, a citizen could call while looking online to verify the correctness of the information.

To move the CC field further forwards, scholars have repeatedly called for new empirical studies from actual use settings, which directly explore citizens' use of multiple channels, reasons for the continued use of traditional channels, and the interactions between different channel types [10-13]. The objective of our research is to address these gaps in the extant CC literature. Herein, we present the results of a sequential mixed method study, employing observations, contextual interviews, and a survey of over 10,000 calls [14] to gain insights in CC in a real-life setting.

Aim of the study and research questions.

This purpose of this study is twofold. First, we aim to explore and measure the types of inquiries which are made by citizens who have adopted digital self-service channels, but still contact public authorities through traditional channels. Second, we seek to understand why these inquiries occur and explore the interplay between different channels, for example when channels are used sequentially or in parallel as one overall service interaction. In order words, we try to understand the multiplex nature of real-life channel choices. To achieve these goals, we present rich empirical examples of actual interaction between citizens and public authorities to put the identified topics into context. The research questions we seek to answer are:

1. To what extent are channel choices multiplex? (RQ1)

2. What causes this multiplexity, i.e. why do citizens that have adopted electronic service channels still choose traditional service channels? (RQ2)

The rest of this paper is organized as follows. The next section presents a brief outline of the literature on channel choice. Section three presents the research setting and method used. Section four discusses the findings. Section five presents concluding remarks, limitations and offers suggestions for future research. 


\section{Channel choice research}

\subsection{Channel choice}

Channel choice (CC) can be seen as the first step in what is called a process of channel behavior [15]. CC refers to "an individual's specific decision to use a medium in a particular communication incident" $[15, \mathrm{p} .163]$ This is followed by the actual interaction (channel use) and an evaluation of that use. This evaluation can create experiences that might trigger future use. CC studies in the e-government literature seek to explain and understand citizens' choice of channels for interacting with government organizations and identify the factors that affect this choice and measure their influence.

Studies have typically considered CC as a multi-nominal selection where users at a singular point in time choose between several channels. For example, Pieterson [8] asked people to choose one channel in a number of hypothetical situations. Similarly, Reddick and Anthopoulos [3] asked people to indicate their channel preferences for a number of hypothetical situations (e.g. solving a problem). However, research shows that rather than being a one-time decision, $\mathrm{CC}$ is actually a more complex process in which channels are used sequentially or in parallel (cf. $[2,10,17])$. Regarding the latter, for example, Madsen and Kræmmergaard [17] found that digital and traditional channels often are used simultaneously, very often this entails people calling while looking at a website. Regarding the former, Pieterson [18] found that citizens typically use multiple channels in one service interaction and often have a first, preferred, channel and move to a second channel when their first choice fails to yield a result. These complex channel usage patterns require government organizations to consider cross-channel integration to ensure that the data and information citizens receive are consistent across all used channels. Scholars have called for further research on channel sequencing [7, $10]$ and suggest direct observations and more in-depth case studies to understand issues relevant to government channel integration [11].

Furthermore, research on citizens' $\mathrm{CC}$ has mainly focused on predefined factors such as channel, task, personal, and situational characteristics (cf. $[8,19])$. For example, Ebbers et al. [19] test a model in which they relate task and channel factors, habits and personal characteristics to $\mathrm{CC}$. While this yields valuable insights about the importance of these variables, it ignores other potential variables (see e.g. [9, 20] for overviews of possible channel choice determinants). This point of criticism is closely related to the majority of CC studies being quantitative in nature and relying on standardized surveys. In addition, many studies have been conducted in controlled and artificial settings, which may limit their explanatory power for actual use settings, cf. e.g. [19]. However, given the integrated nature of channel choices, as mentioned above, more exploratory insight into citizens' actual behaviors is needed [8], [19] as well as case studies and interviews with citizens on their actual channel choices [21]. Thus, instead of enquiring citizens about their preferences, $\mathrm{CC}$ research should rather focus on the process from the initial CC to continued channel use [22], such as through direct observations [3].

To sum up, the existing research on $\mathrm{CC}$ has helped us discover and understand the types of variables that impact singular channel choices and how these variables differ for different tasks, people and situations. However, these insights are inadequate to help 
us understand real-life $\mathrm{CC}$ behaviors, let alone providing prescriptive insights for governments' multi-channel strategies. Therefore, new theories and models are needed to capture the complex, multiplex, nature of real-life channel behaviors.

\subsection{Channel multiplexity}

In communication theory, 'media multiplexity' was originally used to describe communication patterns of distributed scholars, with those with stronger ties using more means of communication [23]. More generally, the concept has been used to describe instances where communication relations are maintained by multiple media [24] and where media multiplexity is associated with a higher communication quality. This idea is similar to the notion of 'intermediality' [25] which refers to a) communication through several discourses at once, b) the combination of separate material vehicles of representation and c) the interrelations among the media as institutions in society. This concept was born out of the observations that, as communication becomes more networked, media themselves become more fluid and interwoven. These ideas of multiplexity and intermediality contrast more traditional notions of media that try to isolate media and focus on the attributes of individual media [26] and see media choices as singular or "immediate incidents" [27]. The reality, of course, is more complicated. Research on technology use has shown that media are often used sequentially in what is considered one use case [26] and media are seen as compliments that can be used to satisfy certain communication needs [28].

We expect similar phenomena to happen in citizen-initiated contacts, where rather than perceiving and choosing channels as being discrete entities, citizens use a combination of channels sequentially or in parallel in what could be considered one service delivery contact. For example, a citizen might go online to a find the phone number of an organization and then call (sequential use) or a citizen could call an organization to confirm the validity of information shown online (parallel use). Thus, channel multiplexity refers to the interrelated (sequential and/or parallel) choice of channels within one overall service interaction and multiplexity appears as a fitting theoretical concept to help us understand real-life channel choices.

\section{$3 \quad$ Research setting}

The study presented here was undertaken in 2017 in the Danish public authority Udbetaling Danmark (UDK) (Disbursement Denmark). UDK was established in 2012 by the Danish government to achieve economic savings in the administration of public benefits. The first author undertook the empirical studies in UDK's Parental leave division in the city of Vordingborg. The division is one of three, which administers parental leave. It consists of 50 caseworkers and two managers across two sections.

UDK follows the Danish e-government strategy whereby digital communication and digital self-service are mandatory for citizens and businesses. UDK's digital and channel strategies also seek to promote automation and digital self-service. The web portal 
borger.dk is the primary means of self-service for citizens, while written communication is handled via digital post, a national e-mail system. Citizens who need help can call UDK. Counter turn-ups are also possible, but rare due to the physical location of UDK's centers. Thus, the interaction primarily occurs online, centered around borger.dk and digital post, while the telephone call are supplementary.

The parental leave scheme.

While most citizens perceive parental leave as a single event, the leave itself consists of a variety of different schemes, such as pregnancy leave, maternity leave, paternity leave and parental leave. Each of these schemes have different underlying legal rules, duration, and payment amounts. For reasons of simplicity, we will refer to these using the joint term parental leave, although the majority of the leave is spent by mothers. When the individual leave schemes matter, we will refer to this specifically. Parental leave benefits are often the main source of income for the person on leave. This distinguished parental leave benefits from other types of public benefits, such as housing benefits, which supplement other sources of income. Therefore, parental leave may create more communication from citizens than other public services.

\section{$4 \quad$ Method}

Our study follows an inductive research strategy [29], informed by CC studies and 'media multiplexity' . Previous CC studies show, that people choose traditional channels when problems occur, while 'media multiplexity' explains that interaction often occur across multiple channels. We seek to explore the nature of problems in digital interaction, and their relationship to citizens' multiplex interaction with UDK.

We apply mixed methods, which is a research approach combining qualitative and quantitative techniques. According to Creswell: “(...) this form of inquiry provides a more complete understanding of a research problem than either approach alone" [30]. Mixed methods studies are conducted according to a pragmatic worldview, encouraging researchers to use the most suitable techniques for gaining insight into practice oriented, real-world problems [30]. We collected the data for our study through an exploratory sequential mixed method, as "a three-phase procedure with the first phase as exploratory, the second as instrument development, and the third as administering the instrument to a sample of a population." [30]. Madsen presents a detailed account of the instrument development [14].

Phase 1. Qualitative data collection

In March 2017, the first author co-listened to 50 calls made to the parental leave section, followed by brief contextual interviews with the callers [14]. By observing actual telephone conversations, we gained insight into channel choices as they occurred in a realworld setting. Moreover, this approach increased the validity of the findings and reduced retrospective sense making, where people's descriptions of their actions (what they say) and motivation are biased, and differ from their actual actions (what they do) $[31,32]$. The co-listening occurred on a citizen line and an employer line. The callers 
were citizens, their representatives, employers, municipal caseworkers, and doctors. Upon answering the telephone, the caseworker asked callers for their permission for the first author to co-listen to the call and interview them. The caseworkers informed callers that the co-listening was voluntary, anonymous, and would not influence their cases in any way. One in ten callers declined to participate; non-participants were mostly doctors and other professionals who said they were too busy.

The first author documented observations and interviews, covering the event which initiated the call, the problems mentioned by the caller, the caseworkers' actions, previous communication with UDK and other authorities, next steps, and final comments by callers. The conversations and interviews were not recorded verbatim, although certain utterances were noted by the first author. Caseworkers and management served as highly knowledgeable informants, whose perspectives contributed to ensuring the validity of the first author's own interpretation of the qualitative data [32].

\section{Phase 2. Instrument development}

In October 2017, the first author collaborated with UDK caseworkers and management to measure the frequency of the discovered topics. We developed a classification scheme to increase caseworkers' classification rates and the validity of the results. The caseworkers suggested additional topics and examples for the scheme and used their own terminology to describe each topic. Exercises and discussions further helped to create a joint understanding of the problems and categories. The caseworkers also helped to solve technical and practical issues surrounding call classification. The final classification scheme covers where in the parental leave process the caller is, and the main topic of the call. Due to limited space, we focus on the topics here.

Phase 3. Administration of survey to register telephone calls

The caseworkers registered 11,600 inbound calls from citizens during October and November 2017. Some calls did not lead to actual casework (wrong number etc.), therefore 10,106 , or $95 \%$ of the completed calls were classified according to topic. The classification system requires the caseworkers to classify each call according to exactly one stage and one topic. However, a conversation may cover several topics and underlying problems. UDK administers maternity leave at three different locations, which receive calls on a rotation basis. According to caseworkers and management, there is no difference in calls received at the different locations. Thus, the collected data should be representative of all calls made to UDK on parental leave.

\section{$5 \quad$ Findings}

This section contains the results of our study. We begin answering our first RQ, on the multiplexity of citizens' CC, based on the observations. Then, we turn to our second $R Q$, why citizens supplement digital interaction with traditional channel use.

First, however, it is important to keep two aspects of the study in mind. The observations presented here occurred in a call-center. Thus, we only get insight into the service interactions where citizens call. We do not get insight into the majority of cases 
where citizens complete an interaction without calling. Second, digital self-service is mandatory in Denmark. In 2017, UDK's parental leave section received 768,000 visits to its website at borger.dk and 340,000 incoming telephone calls on the citizen lines. Thus, website visits still outnumber telephone calls by more than $2: 1$.

\subsection{Citizens' multiplex channel choice}

Of the 50 calls observed in the call center, 32 were made by citizens, 17 by employers and one by a doctor. The majority of callers had previously contacted UDK for the same topic using one or two channels, pointing to the sequential nature of many interactions. Additionally, 14 of the 32 citizens who called had previously received digital post from UDK, either as letters concerning their parental leave or specifications of upcoming leave payments. Excluding contacts with their own company, 18 of the 50 callers had either called other organizations or visited their website for the same service interaction. We cannot make statistical generalizations from 50 observations. However, the majority of the interaction we have observed involves several channels, and roughly a third involve other organizations. These results are supported by the aggregated channel traffic to UDK. To explain these findings, we must study this interaction in more detail. Next, we present the results of the call classification, and then proceed to our observations of the calls and contextual interviews with callers.

\subsection{Description and examples of call topics}

Table 1 presents the distribution of 10,100 calls received by UDK's parental leave section in October and November 2017 as classified by the caseworkers.

Table 1. Call topics to UDK's parental leave section

\begin{tabular}{|c|c|c|}
\hline Topic & Share & Description \\
\hline Planning & $33 \%$ & $\begin{array}{l}\text { Planning the overall leave, individual stages and transition between leave } \\
\text { partners. Includes requests for guidance and specific information, requests } \\
\text { for explanation or confirmation of rules applicability and financial impact. }\end{array}$ \\
\hline Status & $25 \%$ & $\begin{array}{l}\text { Concern the status of an ongoing case and case handling time, prompts for } \\
\text { faster casework, and callers presenting new or correct information to UDK } \\
\text { regarding their case. }\end{array}$ \\
\hline $\begin{array}{l}\text { Monthly } \\
\text { payment }\end{array}$ & $13 \%$ & $\begin{array}{l}\text { Concern the monthly payment of parental leave benefits. Questions concern } \\
\text { when payments are made, the payment amount, and explanations and calcu- } \\
\text { lations behind payments. }\end{array}$ \\
\hline Illness & $10 \%$ & $\begin{array}{l}\text { The mother is ill during pregnancy or maternity leave. Often concern third } \\
\text { party actors (doctors), and documentation regarding illness. }\end{array}$ \\
\hline Salary stop & $6 \%$ & $\begin{array}{l}\text { Salary stop concerns the specific process of switching from receiving a reg- } \\
\text { ular paycheck to receiving parental leave benefits. These calls often involve } \\
\text { the callers' employer and documentation they have provided. }\end{array}$ \\
\hline Refund & $4 \%$ & $\begin{array}{l}\text { Concern instructions for how to refund benefits if too much money has been } \\
\text { received, and special forms for this. }\end{array}$ \\
\hline $\begin{array}{l}\text { Technical } \\
\text { support }\end{array}$ & $2 \%$ & $\begin{array}{l}\text { Requests for technical support on the use of digital self-service applications } \\
\text { for submitting and receiving information, including the use of digital post. }\end{array}$ \\
\hline
\end{tabular}


As shown in Table 1, three topics, planning, status and monthly payment, account for over $70 \%$ of all inbound calls. While the topics are presented as discreet units above, some calls revolved around several topics. In these cases, we asked the caseworker to classify the call according to the topic, which the call initially revolved around.

As we observed these interactions and interviewed callers, we gained insight into the various reasons which caused citizens to call. In many cases, the citizen had several problems, which needed to be solved. Contrary to previous studies, we found that the calls did not just revolve around accessing or understanding information. The caller may also need the caseworker to do something for them. This problem may generate additional channel traffic because such a request cannot be conducted by digital selfservice applications. To demonstrate the complexity of such underlying problems and the multiplexity of the interaction, we present two observed calls.

Example 1. Planning the transition between leave partners (see Figure 1)

A mother's maternity leave is ending, and the father is about to take over. She calls for an understanding of the rules for distributing the leave between parents and the options for extending her leave. She has received letters from UDK and visited borger.dk unsuccessfully. The caseworker informs her of the rules, how to extend her leave, and on the importance of not having any gaps between leave stages. Further, the caseworker says that extension will affect her employer, so the caller needs to inform her employer. The caller asks the caseworker to "spell it out to her" (explain in detail), and for the specific dates for the extended leave. Next, the caller inquires about the economic consequences of shifting from maternity to paternity leave on the household income. Finally, the caller says she wants to extend the leave, but needs to discuss this with the father and with her employer first.

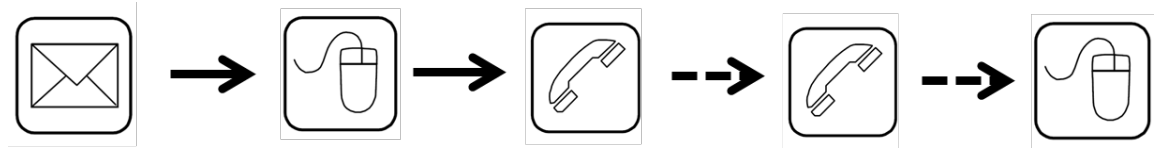

Fig.1 The sequence of interactions in example 1

Here, there are two underlying problems. The caller needs specific information instructions for how to extend her leave. Moreover, she needs to understand the consequences of these actions. Her need does not concern the rules in general, but rather how they apply to her specifically and what their economic consequences are for her family. We also see that the caseworker informs the caller of a problem, which the caller is unaware of - not having gaps in the leave. Finally, we see that the telephone call is at the middle of a series of interactions across several channels and with other actors besides UDK.

Example 2. Status of a case and discrepancy in information (see Figure 2) 
A mother calls because there is a discrepancy between the number of days left of her leave according to a letter from UDK, and information on borger.dk. She has previously called her employer and UDK and been to borger.dk. She has trouble "navigating the parental leave rules". She is logged in to borger.dk while calling. She asks, which of the parents is entitled to the remaining leave. The caseworker informs her of several requirements which the father must meet to be entitled to leave. Next, the caller seeks to confirm that the size of the benefit depends on the employer and the father's collective agreement. She asks for this information in writing so she can forward it to her HR department. She has been unable to find it at borger.dk. The caseworker explains that she cannot reveal information concerning the father without his permission. Finally, they agree that the caseworker will send letters to both parents.

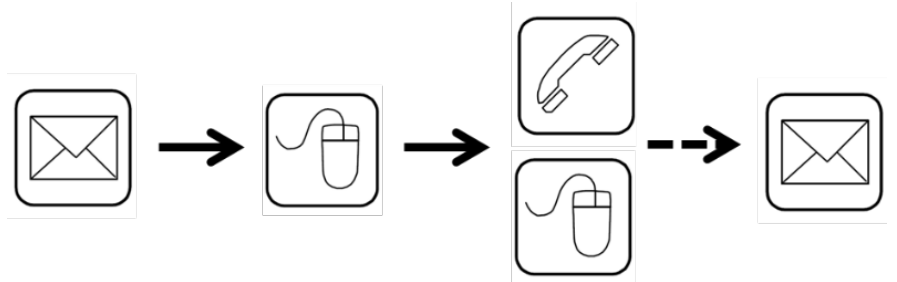

Fig 2. The sequence of interactions in example 2.

Again, the caller both needs information and to understand what it means to her, and what the economic consequences are. However, we also discover another problem, the information presented online does not correspond to the information received in a letter. Therefore, the caller first needs to know which information is correct, and then asks for evidence in the shape of a written letter, which she can forward to her employer. This is an example of an interaction which concern several actors: UDK, two parents, and at least one employer. Thus, the service interaction observed here is a long process occurring sequentially and simultaneously across three different channels: the website, the telephone and letters. Finally, we see that the call is initiated by an outbound letter and ends - for now - with another outbound letter.

\subsection{Citizens' supplementation of digital interaction with traditional channels}

To answer why citizens who have already adopted digital channels still supplement an interaction through traditional channels, we returned to our observations and interviews. We analyzed these according to the underlying problems and needs which appeared during the callers' interaction with UDK or were mentioned in the contextual interviews. We identified five different types of problems and grouped these problems in two overall categories. The five identified problems are presented in Table 2. 
Table 2. The types of problems which cause incoming calls

\begin{tabular}{|c|c|c|c|c|c|}
\hline \multirow{2}{*}{$\begin{array}{l}\text { Category } \\
\text { Problem } \\
\text { type }\end{array}$} & \multicolumn{2}{|c|}{ Information related problems } & \multicolumn{3}{|c|}{ Action related problems } \\
\hline & $\begin{array}{l}\text { leed for infor- } \\
\text { mation }\end{array}$ & $\begin{array}{l}\text { Need for explana- } \\
\text { tion }\end{array}$ & $\begin{array}{l}\text { Need for docu- } \\
\text { mentation }\end{array}$ & $\begin{array}{l}\text { Need for neg } \\
\text { tiation }\end{array}$ & $\begin{array}{l}\text { - Need for } \\
\text { revision }\end{array}$ \\
\hline Examples & $\begin{array}{l}\text { - Confirmation } \\
\text { for submitted } \\
\text { information } \\
\text { - Guidelines for } \\
\text { action } \\
\text { - Status of case } \\
\text { - Payments }\end{array}$ & $\begin{array}{l}\text { - Of rules and } \\
\text { consequences } \\
\text { - For UDK deci- } \\
\text { sions and received } \\
\text { payments }\end{array}$ & $\begin{array}{l}\text { - Receipts } \\
\text { - Case files, to } \\
\text { self or third } \\
\text { party }\end{array}$ & $\begin{array}{l}\text { - Concerning } \\
\text { interpretation } \\
\text { of rules } \\
\text { - For faster } \\
\text { casework } \\
\text { - For faster } \\
\text { payment }\end{array}$ & $\begin{array}{l}\text { - To regis- } \\
\text { tered or sub- } \\
\text { mitted infor- } \\
\text { mation } \\
\text { - To case and } \\
\text { benefits re- } \\
\text { ceived }\end{array}$ \\
\hline
\end{tabular}

Information related problems concern people's access to, and understanding of, information from the public authorities regarding public benefits. Information related problems are well-known known in the $\mathrm{CC}$ literature. They cover:

- Need for information. The caller knows what information they are seeking, but not necessarily where to access it. They may call simply because this is quick and convenient. The problems belonging to this group are well-suited for digitization, but at the time of the study, many of the requested features did not exist at the parental leave section of borger.dk.

- Need for explanation. The caller needs an explanation for the information, its application and consequences to their specific case, or to be certain their interpretation is correct. Offering explanations to people's specific cases is difficult online as it requires customization and decision-making, not merely presenting information.

Action related problems cover situations, where the caller needs the caseworker to perform an action for them. These are harder to digitalize because of their more complex nature and need for the caseworkers to exercise discretion. They cover:

- Need for documentation. The caller needs documentation about their case to be sent, either to themselves or a third party. Unlike the need for information, it is not necessarily the information itself which matters. Rather the documentation is needed as evidence to begin, or of a completed, administrative process.

- Need for negotiation. The caller seeks to persuade the caseworker to adopt their perspective or set act outside established procedures. An example could be to make an unscheduled payment or look at the caller's specific case, thereby speeding up processing times. This type of need appears to be very difficult to digitize as negotiation and persuasion requires a human partner.

- Need for revision. The caller needs UDK to make changes to their case or update specific information, either submitted by themselves or by a third party. Such actions can and have been digitized in a public context. It is, however, important to have control mechanisms in place. 


\section{Conclusions \& Discussion}

The goal of this paper was to explore the potentially multiplex nature of channel choices by citizens when interacting with governments. RQ1 focused on the extent to which channel choices are multiplex. While not being a quantitative, confirmatory study, our research does indicate a large proportion of channel interactions to be multiplex (i.e. the choice of multiple channels for what can be considered one interaction). This provides an important, possible, explanation for the observation that the overall number of channel interactions are increasing in many countries and citizens continue to use traditional channels after adopting digital service channels.

Our second research question (RQ2) focused on the causes of this multiplexity. Our analysis identified two main groups of causes. The first is information related problems, which result from people not being able to find the needed information and thus choosing a second channel or from citizens needing additional explanation or closure about the correctness and/or validity of the information. While these problems may stem from flaws in the design of a channel (e.g. the degree to which information is retrievable), they could also result from a lack of richness [16] of the channel to convey the required message. Surprisingly, there were few inquiries regarding access to and use of the digital channels. This indicates that citizens have the necessary digital skills, but lack knowledge of public services to use self-service application. The second group of causes are action related problems, which trigger some kind of transaction that might not be done in another original channel (e.g. the need for documentation, negotiation or revision of data).

\section{Limitations and Future Studies}

The study presented here is exploratory and provides the first insights into real-life channel choice behaviors and their often complex and multi-facetted nature. However, it has some limitations. While co-listening to calls and interviewing the callers, we did not explicitly ask for the problems that caused them to call UDK nor their channel choices. Rather, we deduced the problems from the cases the callers described. Furthermore, our study focused on welfare services in Denmark, which represents a mature research setting where social trust is high. Although this setting differs from other countries with non-mandatory e-government use and less social trust, we assume that our findings are valid for different cultural contexts as well.

More research on this topic is needed especially in three areas. The first is further explorations about the sequential and/or parallel nature of channel interactions to fully understand all combinations and their causes. The second is confirmatory research testing the extent to which these multiplex channel choices happen in real life. The third is research exploring ways to reduce multiplexity in order to improve channel efficiencies, for example through the design of channels, improved communication or channel marketing. Further, while we introduce the concept of channel multiplexity, this is by no means a fully fledged theory and more theoretical work is needed to fully understand the concept and embed it in the existing theories and extant CC research. 


\section{References}

1. Layne, K., Lee, J.W.: Developing fully functional E-government: A four stage model. Gov. Inf. Q. 18, 122-136 (2001).

2. Madsen, C.Ø., Kræmmergaard, P.: How to Migrate Citizens Online and Reduce Traffic on Traditional Channels Through Multichannel Management: A Case Study of Cross-Organizational Collaboration Surrounding a Mandatory SelfService Application. In: IGI Global (ed.) Innovative Perspectives on Public Administration in the Digital Age. pp. 121-142 (2018).

3. Reddick, C., Anthopoulos, L.: Interactions with e-government, new digital media and traditional channel choices: citizen-initiated factors. Transform. Gov. People, Process Policy. 8, 398-419 (2014).

4. Statistics Denmark: ICT household survey 2016. (2016).

5. European Commission: Digital Economy and Society Index (DESI) 2018 Country Report Denmark. (2018). https://doi.org/10.2118/140253-MS.

6. Ebbers, W.E., Pieterson, W.J., Noordman, H.N.N.: Electronic government: Rethinking channel management strategies. Gov. Inf. Q. 25, 181-201 (2008).

7. Madsen, C.Ø., Hofmann, S.: Multichannel Management in the Public Sector A Literature Review. Electron. J. e-Government. (2019).

8. Pieterson, W.: Citizens and Service Channels: Channel Choice and Channel Management Implications. Int. J. Electron. Gov. Res. 6, 37-53 (2010).

9. Madsen, C.Ø., Kræmmergaard, P.: Channel Choice: A Literature Review. In: Tambouris, Janssen, Schol, Wimmer, and Tarabanis (eds.) Electronic Government: Proceedings of the 14th IFIP WG 8,5 International Conference, EGOV 2015. LNCS Springer, Thessaloniki, Greece (2015).

10. Reddick, C., Turner, M.: Channel choice and public service delivery in Canada: Comparing e-government to traditional service delivery. Gov. Inf. Q. 29, 1-11 (2012).

11. Kernaghan, K.: Changing channels: Managing channel integration and migration in public organizations. Can. Public Adm. 56, 121-141 (2013).

12. Ganapati, S., Reddick, C.G.: The Use of ICT for Open Government in U.S. Municipalities: Perceptions of Chief Administrative Officers. Public Perform. Manag. Rev. 37, 365-387 (2014).

13. Lindgren, I., Madsen, C.Ø., Hofmann, S., Melin, U.: Close encounters of the digital kind: A research agenda for the digitalization of public services. Gov. Inf. Q. (2019).

14. Madsen, C.Ø.: Translating Telephone Calls To Spreadsheets: Generating Knowledge on Citizen Multichannel Behavior in Collaboration With Caseworkers. Electron. J. e-Government. 16, 106-118 (2018).

15. Willem, P., Teerling, M.: Citizen Behavior in a Multi-Channel Environment. Proceeding 9th Annu. Int. Digit. Gov. Res. Conf. 387-388.

16. Trevino, L.K., Webster, J., Stein, E.W.: Making Connections: Complementary Influences on Communication Media Choices, Attitudes, and Use. Organ. Sci. 11, 163-182 (2000).

17. Madsen, C.Ø., Kræmmergaard, P.: The efficiency of freedom. Single parents' 
domestication of mandatory e-government. Gov. Inf. Q. (2015).

18. Pieterson, W.: Channel Choice. Citizens' Channel Behavior and Public

Service Channel Strategy.,

https://www.utwente.nl/ctit/cfes/docs/proefschriften/2009-

Channel_Choice_Final_web.PDF, (2009).

19. Ebbers, W.E., Jansen, M.G.M., Pieterson, W.J., van de Wijngaert, L.A.L.: Facts and feelings: The role of rational and irrational factors in citizens' channel choices. Gov. Inf. Q. 33, 506-515 (2016).

20. Pieterson, W., van Dijk, J.: Channel choice determinants; an exploration of the factors that determine the choice of a service channel in citizen initiated contacts. In: 8th Annual International Conference on Digital Government Research (dg.o 2007). pp. 173-182. Digital Government Research Center, Philadelphia, Pennsylvania (2007).

21. Schmidthuber, L., Hilgers, D.: Browse or Brush? An Exploration of CitizenGovernment Interaction in the Municipal Realm. In: Proceedings of the 50th Hawaii International Conference on System Science (HICSS-50). pp. 24182427 (2017).

22. Ebbers, W.E., Jansen, M.G.M.M., van Deursen, A.: Impact of the digital divide on e-government: Expanding from channel choice to channel usage. Gov. Inf. Q. 33, 685-692 (2016).

23. Haythornthwaite, C.: Social networks and Internet connectivity effects. Information, Commun. Soc. 8, 125-147 (2005).

24. Ledbetter, A.M., Mazer, J.P.: Do online communication attitudes mitigate the association between Facebook use and relational interdependence? An extension of media multiplexity theory. New Media Soc. (2014).

25. Jensen, K.B.: Intermediality. In: The International Encyclopedia of Communication Theory and Philosophy. John Wiley \& Sons, Inc (2016).

26. Stephens, K.K., Sørnes, J.O., Rice, R.E., Browning, L.D., Sætre, A.S.: Discrete, sequential, and follow-up use of information and communication technology by experienced ICT users. Manag. Commun. Q. (2008).

27. Saunders, C., Jones, J.W.: Temporal Sequences in Information Acquisition for Decision Making: A Focus on Source and Medium. Acad. Manag. Rev. (2011).

28. Dutta-Bergman, M.J.: Complementarity in Consumption of News Types Across Traditional and New Media. J. Broadcast. Electron. Media. 48, 41-60 (2004).

29. Blaikie, N.: Approaches to social inquiry. Polity (2010).

30. Creswell, J.W.: Research Design. Qualitative, Quantitative, and Mixed Methods Approaches. SAGE, London, UK (2014).

31. Blomberg, J., Giagomi, J., Mosher, A., Swenton-Wall, P.: Ethnographic field methods and their relation to design. In: Schuler, D. and Namioka, A. (eds.) Participatory Design: Principles and Practices. CRC Press, New York (1993).

32. Eisenhardt, K., Graebner, M.: Theory building from cases: Opportunities and challenges. Acad. Manag. Rev. 50, 25-32 (2007). 